\title{
POLÍTICAS INDUSTRIAIS PARA O SETOR AUTOMOTIVO: UMA COMPARAÇÃO SOBRE O BRASIL E A CHINA ENTRE AS DÉCADAS DE 1950 E 1990
}

\section{INDUSTRIAL POLICIES FOR THE AUTO SECTOR: A COMPARISON ON BRAZIL AND CHINA BETWEEN THE 1950s AND 1990s}

\author{
Fernando Marcus Nascimento Vianini*
}

\begin{abstract}
Resumo: O presente texto possui como objetivo comparar os principais resultados das políticas industriais automotivas no Brasil e na China em termos de propriedade do setor e de produção de veículos. Delimitamos as políticas em dois períodos, o primeiro sendo o de instalação do setor na década de 1950 e o segundo, a era de reformas de mercado iniciadas na China ao final da década de 1970 e no Brasil na década de 1980. Para o Brasil, foram destacadas as políticas do GEIA e os acordos das Câmaras Setoriais. Para a China, ressaltamos as políticas da era de Mao e as políticas de 1987 e de 1994. As fontes utilizadas na análise foram as políticas, as regulações e a vasta literatura acerca do tema, que nos permitiram concluir que enquanto no Brasil o capital nacional foi gradualmente empurrado para os segmentos de menor tecnologia pelo capital externo, na China, a entrada do capital externo foi condicionada à transferência de tecnologia, ressaltando a centralidade do desenvolvimento tecnológico nas políticas industriais chinesas mais recentes.
\end{abstract}

Abstract: The present text aims to compare the main results of automotive industrial policies in Brazil and China in terms of firms' ownership and vehicle production. We delimit the policies in two periods, the first being the installation of the sector in the 1950s and the second, the era of market reforms initiated in China in the late 1970s and Brazil in the 1980s. For Brazil, The policies of the GEIA and the agreements of the Sectoral Chambers were highlighted. For China, we emphasized the Mao-era policies and the policies of 1987 and 1994. The sources used in the analysis were the policies, the regulations and the vast literature on the subject, which allowed us to conclude that while in Brazil the national capital was gradually pushed into the lower technology segments by the foreign capital, in China, the entrance of foreign capital was conditioned to the technology transfer, stressing the centrality of technological development in the latest Chinese industrial policies.

Palavras-chave: Indústria, Setor Automotivo, Política Industrial

Key-words: Industry, Automobile Sector, Industrial Policy

Introdução

O presente trabalho busca realizar uma comparação entre alguns dos resultados das políticas industriais para o setor automotivo lançadas pelos governos executivos do Brasil e da China e seus principais resultados e legados em dois períodos, o primeiro

\footnotetext{
* Doutorando em História pelo Programa de Pós-Graduação em História da Universidade Federal de Juiz de Fora (UFJF), email de contato: fernandomvianini@gmail.com.
} 
sendo o de instalação deste setor, a partir da década de 1950, e o segundo, o das reformas de mercado, na China iniciadas ao final da década de 1970 e no Brasil, entre finais da década de 1980 e início da década de 1990. Através da utilização de fontes primárias tais como as leis e as políticas - e da literatura acerca do tema, avaliaremos os resultados destas políticas em termos de propriedade da indústria e os números da produção de veículos.

A primeira questão que se impõe neste trabalho é por que comparar as trajetórias de países tão distintos como o Brasil e a China. Giovanni Arrighi (1997) classificou as economias nacionais inseridas no capitalismo como centrais, semiperiféricas e periféricas, tendo como base o controle que cada economia nacional possui sobre os fatores que possibilitam maior agregação e retenção de valor no espaço econômico. Inseridos na semiperiferia, Brasil e China procuraram se equiparar com os países centrais, principalmente a partir de meados do século XX. Alice Amsden (2009), ao analisar o processo de catching up empreendido por um conjunto de países de industrialização tardia e que não haviam desenvolvido capacidades administrativas e tecnológicas suficientes, identificou como estes países, através de diferentes abordagens, procuraram superar sua defasagem em relação às nações desenvolvidas. Deste modo, o Brasil optou pelo desenvolvimentismo típico dos países latino-americanos, com a combinação entre intervenção estatal, capital nacional e capital privado, enquanto a China optou pela via socialista, com forte presença do Estado e das empresas estatais.

Em ambos os países, a opção pelo setor automotivo como motor do desenvolvimento econômico se deu pelo fato de, na década de 1950, o setor se constituir como um dos que mais exigia desenvolvimento tecnológico e pelos efeitos de arrasto e de encadeamento que a produção de automóveis gerava sobre os demais setores. Contudo, a forma como se deu a instalação e sua posterior evolução se diferiu nestes dois casos. Segundo o novo institucionalismo histórico, as escolhas realizadas no momento de formação das instituições ou políticas exercem um efeito de constrangimento sobre seu desenvolvimento futuro em função de uma tendência à inércia das instituições e políticas, bloqueando ou, ao menos, dificultando a ocorrência de alterações posteriores. Assim, uma vez que certa trajetória tenha sido adotada, se faz necessário um grande esforço - ou mesmo um choque externo - para alterar a direção e o curso das instituições (BERNARDI, 2012). Deste modo, o conceito de dependência da trajetória foi amplamente utilizado na tentativa de compreender a importância da sequência temporal 
e do desenvolvimento, ao longo do tempo, de eventos e processos sociais; ressaltando, pois a importância da história e como o legado passado pode condicionar o futuro.

Brian Arthur (1990) identificou que a produção de bens intensivos em conhecimento e tecnologia - como os automóveis na década de 1950 - pode ativar processos de autorreforço, que faz com que cada novo passo dado no sentido desta atividade produz maiores benefícios, fornecendo maiores incentivos aos atores para investirem nesta atividade e mantendo a mesma trajetória. Paul Pierson (2004), por seu turno, inferiu que tecnologias, instituições e políticas estariam sujeitas à dependência da trajetória. Sua análise partiu do princípio que, no momento formativo inicial, uma opção institucional ou política é tomada - se configurando como a conjuntura crítica -, e cada passo nesta trajetória implica um ciclo de autorreforço que torna as demais alternativas cada vez menos prováveis e seus custos mais proibitivos. ${ }^{1}$ Ainda que muitas críticas sejam dirigidas ao conceito de dependência da trajetória ${ }^{2}$, consideramos que este conceito ajuda a esclarecer uma série de questões acerca da trajetória de desenvolvimento dos setores automotivos do Brasil e da China.

Identificamos, pois, dois momentos fundamentais para o desenvolvimento deste setor nestes dois países: a fase de instalação do setor, também chamada de catching up que se estendeu no Brasil de 1956 ao final do regime militar, e na China de 1956, data da inauguração da primeira planta automotiva do país, a 1978 - e a fase de reformas prómercado - que no Brasil se iniciou na década de 1980, aprofundada na década seguinte, e na China, por sua vez, se estendeu do final da década de 1970 ao final da década de 1990. Para o Brasil, na primeira fase, a política do Grupo Executivo da Indústria Automotiva (GEIA) exerceu o controle sobre a instalação do setor e, na segunda fase, destacamos as Câmaras Setoriais. Para a China, a instalação do setor automotivo se deu sob o controle de Mao e, após as reformas, duas políticas foram direcionadas para o setor, a de 1987 e a de 1994.

Este artigo está dividido em quatro partes, além desta introdução. Na segunda seção, abordaremos a trajetória do Brasil, destacando a formação de um setor montador dominado pelo capital externo e de um setor fornecedor dominado pelo capital nacional e suas transformações até a década de 1990. Na terceira seção, nos voltamos para a trajetória da China, onde se formou um setor automotivo de propriedade estatal, com

\footnotetext{
${ }^{1}$ Um dos aspectos que Pierson (2004) atribuiu aos processos de autorreforço é que, no longo prazo, o resultado final pode gerar menores benefícios do que outra das alternativas disponíveis no início da sequência.

${ }^{2}$ Ver: BERNARDI (2012).

CSOnline - Revista Eletrônica de Ciências Sociais, Juiz de Fora, n. 25 (2017), pp. 1-296.
} 
características particulares, até as reformas econômicas, que possibilitaram a entrada do capital externo no setor automotivo. Por fim, na quarta seção, partimos para a comparação dos resultados destas políticas e para a conclusão destas reflexões.

O caso brasileiro: a gradual redução da participação do capital nacional

Embora a literatura especializada considere os governos de Getúlio Vargas como a origem institucional do setor automotivo, em que os quadros físicos, legais e infraestruturais foram estabelecidos, foi efetivamente no governo Juscelino Kubistchek, através do Plano de Metas e do GEIA, que o setor foi instalado no Brasil (SHAPIRO, 1994, LATINI, 2007). ${ }^{3}$ A implantação do setor automotivo foi pensada para a resolução do problema da balança de pagamentos, todavia, ganhou contornos mais estratégicos quando o setor passou a ser visto como meio para garantir uma rápida industrialização e causar efeitos de derramamento sobre os demais setores da economia. ${ }^{4}$ A implantação do setor automotivo ainda resolveria o problema dos transportes e da integração física do país, ao mesmo tempo em que se traduziria no apoio da classe média ao governo federal, já que o projeto esteve voltado para atender o mercado doméstico, e apoio da burguesia industrial e dos militares (SHAPIRO, 1997).

A partir do decreto 39.412 de 16 de junho de 1956 (BRASIL, 1956), foram estabelecidas as diretrizes básicas relativas à Indústria Automobilística Brasileira, a competência e a autoridade dos órgãos executivos que se encarregariam de aplicar tais diretrizes, a importação de equipamentos com subsídios via Instrução 113 da SUMOC, a definição de prazos e dos requerimentos de conteúdo local e a criação do Grupo Executivo da Indústria Automobilística (GEIA), cujas funções seriam a execução e supervisão das diretrizes básicas do decreto, o julgamento dos projetos apresentados pelas fabricantes de veículos, e o estabelecimento dos Planos Nacionais Automobilísticos para as várias linhas de veículos, entre outras medidas.

\footnotetext{
${ }^{3} \mathrm{O}$ objetivo central do Plano de Metas era o de transformar a economia brasileira de exportadora de matérias primas em manufatureira. O Plano era formado por trinta metas de expansão para o desenvolvimento econômico e social do Brasil, que tinham como objetivo a superação dos pontos de estrangulamento para o desenvolvimento econômico brasileiro, a implantação de indústrias em diversos setores, e o equilíbrio da balança comercial através da nacionalização da produção. A Meta 27 consistia na implantação do setor automotivo (FARO; SILVA, 1991; LEOPOLDI, 1991).

${ }^{4}$ De acordo com Limoncic (1997), a implantação do setor automotivo criaria importantes efeitos-cascata, não somente em outros setores, mas também sobre diversos outros pontos do Plano de Metas, como as metas relacionadas ao petróleo, metalurgia e metais, borracha e transporte.
}

CSOnline - Revista Eletrônica de Ciências Sociais, Juiz de Fora, n. 25 (2017), pp. 1-296. 
Definida a instalação do setor, restava a questão sobre o capital a ser investido. Iria o Estado investir ou seria o capital nacional privado a liderar o setor? Seria escolhido realizado um sistema de campeões nacionais, ou predominaria o capital externo e as multinacionais? O GEIA constatou que o capital privado nacional era muito fraco para satisfazer os requerimentos tecnológicos e de capital para a indústria automotiva. Anteriormente, as próprias fabricantes de autopeças informaram à Vargas sobre sua incapacidade de financiar qualquer projeto de veículo nacional. Nem mesmo a Ford ou a GM, que tinham a maior experiência no Brasil, possuíam tecnologias licenciadas ou joint ventures formadas em qualquer lugar do mundo. E, mesmo que alguma empresa brasileira conseguisse licenciamento, ela teria gastos em bens de capital e com a tecnologia importada, o que também afetaria o balanço de pagamentos (SHAPIRO, 1994, LATINI, 2007). Deste modo, a propriedade estatal no setor automotivo foi logo descartada por causa da limitação da capacidade físcal do Brasil, uma vez que o Estado possuía poucos instrumentos pelos quais poderia acumular recursos, devido ao campo político desfavorável e ao direcionamento das estatais para os setores ligados à infraestrutura, como a siderurgia. ${ }^{5}$

A partir da criação do GEIA, foram instituídos decretos que guiariam a implantação do setor de caminhões (decreto 39.568, julho de 1956), jipes (decreto 39.569, julho de 1956), camionetas, furgões e caminhões leves (decreto 39.676-A, julho de 1956), carros de passeio (decreto 41.018, fevereiro de 1957) e tratores agrícolas (decreto 47.473, dezembro de 1959). As políticas foram feitas para garantir que as empresas transnacionais fizessem amplos investimentos para garantir seu comprometimento ao projeto. Os decretos efetivamente fecharam o mercado brasileiro para as importações e forçavam as firmas a aumentarem o nível de conteúdo local para, em contrapartida, receberem uma série de incentivos fiscais. Ao oferecer incentivos por um período limitado, o governo fazia com que as empresas que não se empenhassem desde o princípio ficassem em desvantagem frente àquelas que começaram anteriormente. As autoridades teriam o poder de reter o capital remetido das firmas que falhassem em cumprir o cronograma de metas, assim como suspender os subsídios após a data definida. Para assegurar seus objetivos, o GEIA, ao aprovar algum projeto, exigia uma série de contrapartidas em troca de um

\footnotetext{
${ }^{5} \mathrm{O}$ único exemplo de investimento estatal no setor automotivo foi a Fábrica Nacional de Motores (FNM), que esteve associada à estratégia do Estado Novo de criar uma infraestrutura industrial no país, convertida de fabricante de motores para aviões em produtora de caminhões em parceria com a montadora italiana Isotta Fraschini até 1950, quando um novo acordo foi assumido com a Alfa Romeo. Em seu período de atuação, a FNM atravessou por diversas crises e sobreviveu ao discurso liberal até 1968, quando o Regime Militar privatizou a empresa, vendendo-a a Alfa Romeo, da Itália (RAMALHO, 1997).

CSOnline - Revista Eletrônica de Ciências Sociais, Juiz de Fora, n. 25 (2017), pp. 1-296.
} 
pacote de estímulos. As empresas deveriam cumprir uma agenda de progressiva nacionalização da produção e de preços dos veículos ao mesmo tempo em que cumpriam metas de produção (SHAPIRO, 1994, NEGRO, 1997).

Dos dezoito projetos enviados ao GEIA, onze foram postos em prática. Das firmas que iniciaram a produção no Brasil dentro do programa do GEIA, três eram controladas pelo capital nacional (Willys-Overland, Vemag e FNM), duas eram joint ventures 50-50 entre o capital nacional e o estrangeiro (Mercedes-Benz e Simca) e seis eram controladas ou subsidiárias totalmente controladas pelo capital externo (Ford, GM, Volkswagen, International Harvester, Scania Vobis e Toyota).

O objetivo final da política era a produção de 170 mil veículos, com 90 a 95\% de conteúdo nacional em peso dos veículos. Em 1961, seis anos após a implantação do programa, as onze firmas produziam 145 mil veículos, com cerca de $87 \%$ de conteúdo local em valor, o que superava as expectativas da política (ANFAVEA, 2015). Em 1964, após a absorção do GEIA pelo Grupo Executivo da Indústria Mecânica (GEIMEC), a única legislação específica para a indústria automotiva com poderes de coordenar ou coibir a atuação das empresas do setor foi extinta. Sem possuir uma legislação específica, a indústria passou a se autorregular com base no mercado (ROEHE, 2011).

Assim, a política de instalação do setor cumpriu seu objetivo. O Estado ficou com o papel de regulador dos investimentos e, em termos de propriedade, o capital externo responsável pelas montadoras e ao capital nacional foi relegada a maior parcela do setor fornecedor de peças e componentes para o setor, embora estivesse presente no setor montador até o início da década de 1960. A produção de veículos era voltada para o mercado interno e concentrada no estado de São Paulo. ${ }^{6}$ Entre 1957 e 1962, a produção total de automóveis no Brasil saltou de 30 mil unidades para 191 mil. Apesar da queda em 1963, a produção manteve uma trajetória ascendente, ultrapassando o valor de um milhão de unidades em 1978 (ANFAVEA, 2015).

Importantes transformações ocorreram no capitalismo mundial entre as décadas de 1970 e 1980. As crises do petróleo e a alteração da taxa de juros provocaram efeitos devastadores nas economias dependentes de empréstimos externos, como o Brasil. Ao longo da década de 1980, uma série de problemas macroeconômicos se acumulou, como o déficit nas contas e a inflação, abrindo espaço para o projeto neoliberal, que saiu vitorioso nas eleições de 1989. Fernando Collor assumiu a presidência em 15 de maio de

\footnotetext{
${ }^{6}$ Apenas o Rio de Janeiro contava com a presença da FNM. Posteriormente, na década de 1970, Minas Gerais e Paraná receberam suas plantas montadoras, a Fiat e a Volvo, respectivamente.

CSOnline - Revista Eletrônica de Ciências Sociais, Juiz de Fora, n. 25 (2017), pp. 1-296.
} 
1990 e anunciou um plano drástico de estabilização, cujas medidas convergiam com as propostas neoliberais, como a abertura comercial, a redução do papel do Estado como produtor de bens e serviços e a reorganização da administração pública federal, exemplificadas pela Política Industrial e de Comércio Exterior (PICE) e pelo Plano Nacional de Desestatização (PND) (CASTRO, 2011). Para o setor automotivo, o governo permitiu a importação de veículos, almejando que, com o aumento da competitividade, as empresas aqui instaladas se atualizassem e investissem em tecnologia. Estas políticas eliminaram os controles quantitativos sobre as importações, reduziram as tarifas e suprimiram os incentivos e os subsídios. Contudo, as medidas de Collor não propunham uma contrapartida para a indústria nacional, principalmente para o setor fornecedor, que se viu despreparada para competir com as importações.

No contexto de congelamento de preços orquestrado pelo Plano Collor, o governo federal recorreu às Câmaras Setoriais, espaços de diálogo criados no governo Sarney, sem obter resultados expressivos, uma vez que o consumo foi reduzido e a produção de veículos estagnou. Em maio de 1991, as Câmaras foram redefinidas como campo de negociação tripartite entre Estado, indústria e trabalhadores, sendo a elas atribuída a função de elaboração de políticas industriais e de busca de soluções conjuntas e de estratégias de reestruturação dos setores industriais. Ainda que os trabalhadores permanecessem com uma postura de desconfiança, o empresariado enxergou nas Câmaras a oportunidade para ter suas demandas atendidas (ANDERSON, 1999, SAKER, 2006).

Neste cenário de crise e estagnação econômica, a Câmara Setorial Automotiva conseguiu articular três acordos, de médio e longo prazo, para a recuperação do setor. $\mathrm{O}$ primeiro acordo foi formalizado durante o governo Collor, o segundo na gestão de Itamar Franco e o terceiro no governo de Fernando Henrique Cardoso. Neste período em que o governo federal se destacou pela adoção e divulgação de medidas de cunho neoliberal, os acordos para o setor automotivo possuíam inspiração desenvolvimentista, incluindo metas para produção, investimento e geração de empregos. ${ }^{7}$

O Primeiro Acordo foi construído a partir das reuniões de dezembro de $1991 \mathrm{e}$ definiu as responsabilidades do governo, empresas e trabalhadores para a recuperação do

\footnotetext{
${ }^{7}$ Estes acordos, porém, não foram concretizados sem mobilizações ou disputas intensas entre os atores. Quando o governo anunciou propostas de incentivo às importações, os trabalhadores e parte do empresariado ameaçaram abandonar os grupos de trabalho. Outro episódio marcante foi a paralisação dos trabalhadores da Volkswagen por duas horas após a empresa anunciar o reajuste no preço dos veículos, sem que este tema tivesse sido discutido anteriormente nas Câmaras (SAKER, 2006). CSOnline - Revista Eletrônica de Ciências Sociais, Juiz de Fora, n. 25 (2017), pp. 1-296.
} 
setor. Com duração entre 27 de março e 30 de junho de 1992, seus objetivos eram a redução em $22 \%$ do preço dos automóveis e dos veículos comerciais leves, sendo $12 \%$ refletindo a redução de impostos - sendo 6\% do ICMS e 6\% do IPI - e 10\% refletindo a redução da margem de lucros da cadeia produtiva - sendo $4.5 \%$ de responsabilidade das montadoras, $3 \%$ das fornecedoras e $2.5 \%$ das concessionárias -; a manutenção do nível de emprego até o dia 30 de junho de 1992, posteriormente estendido para 31 de julho; o relançamento de consórcios para carros de passeio, a abertura de um programa de financiamento para a compra de caminhões, ônibus e tratores, entre outras medidas (ANDERSON, 1999; SAKER, 2006).

O Segundo Acordo automotivo foi assinado em 15 de fevereiro de 1993, já com Itamar Franco na presidência, reforçou as diretrizes anteriores e trouxe novas medidas. Entre seus principais pontos estavam o estabelecimento de metas de produção gradativas, sendo 1.2 milhão para 1993, 1.35 milhão para 1994, 1.5 milhão pra 1995 e 2 milhões pra 2000; a fixação de metas de investimento de 20 bilhões de dólares em toda cadeia produtiva até 2000, sendo 10 bilhões de responsabilidade das montadoras, 6 bilhões das fornecedoras, 3 bilhões pelos segmentos de forjaria, matérias-primas, fundição e concessionárias e 1 bilhão pelo segmento de pneumáticos; a redução média do preço de veículos em $10 \%$, resultado da diminuição de impostos, como redução do IPI de $6 \%$ para automóveis e a redução de ICMS nos estados produtores, e redução da margem de lucro das empresas, sendo $3 \%$ das montadoras, $1,2 \%$ das fornecedoras e $0,8 \%$ das concessionárias; a ampliação dos prazos de consórcio; a manutenção dos empregos, a criação de 91 mil postos de trabalho, sendo 4 mil apenas nas montadoras, entre outras medidas (ANDERSON, 1999). Paralelamente ao Segundo Acordo, o governo assinou o Decreto n ${ }^{\text {0 } 799, ~ d e ~} 17$ de abril de 1993 (BRASIL, 1993), que diminuía o IPI dos carros populares para $0,1 \%$, objetivando estimular a produção de veículos de pequeno porte, com cilindrada inferior a 1.000 e preço mais acessível. A partir do decreto, a produção e as vendas de carros populares começaram a crescer. Entre 1992 e 1995, os carros populares passaram de $14,4 \%$ da produção para 53,8\%.

Entre 1994 e 1995, as relações entre governo e as empresas se deterioraram. Unilateralmente, em setembro de 1994, o governo federal decidiu modificar o imposto de importação, adiantando o cronograma da Tarifa Externa Comum do Mercosul, fixando-o em $20 \%$ e visando combater os problemas de desabastecimento do mercado interno, causando um aumento expressivo das importações (ANDERSON, 1999). No início de 1995, a Câmara do Setor Automotivo se reuniu para discutir o processo de reversão desta CSOnline - Revista Eletrônica de Ciências Sociais, Juiz de Fora, n. 25 (2017), pp. 1-296. 
abertura econômica, procurando o estabelecimento de um cronograma de redução da alíquota de impostos de importação mais gradual. Em 6 de fevereiro de 1995 foi assinado o Terceiro Acordo, que definiu as alíquotas de importação em 32\% em 1995, 30\% em 1996, 28\% em 1997, 26\% em 1998, 24\% em 1999, 22\% em 2000 e $20 \%$ em 2001; a reavaliação da estrutura do IPI sobre automóveis; a definição de uma política comum do regime automotivo em todo Mercosul, entre outras medidas. Em 1995, através do decreto 1.391, o imposto de importação foi elevado para 32\%, seguindo o cronograma estabelecido pelo terceiro acordo (BRASIL, 1995).

Entre os resultados das Câmaras, as metas de produção foram atingidas, exceto a meta de 2000, em decorrência da abertura econômica e da vulnerabilidade externa do país demonstrada pelos eventos posteriores à Crise Asiática de 1997. Entre 1990 e 1994, a produção de veículos no Brasil saltou de 914 mil unidades para 1.581 milhão (ANFAVEA, 2015). Contudo, as metas de geração de emprego não foram alcançadas e, de acordo com Bedê (1997), no setor fornecedor o nível de empregos foi reduzido ainda mais, devido ao processo de abertura econômica e de reestruturação do setor. Shapiro (1996) afirmou que do ponto de vista dos trabalhadores, as câmaras setoriais foram um fracasso. Entre 1990 e 1993, a produção cresceu 80\%, empregando 11\% a menos. Além da não alteração sobre a taxa de empregos, como acordado nas câmaras, não ocorreu aumento salarial real.

Em termos de propriedade, a predominância do capital externo sobre o setor montador se manteve. As poucas empresas nacionais foram compradas pelas montadoras estrangeiras ainda na década de 1960, como a Willys, a Vemag e a FNM. Ademais, as empresas transnacionais foram as grandes beneficiadas pelos três acordos, uma vez que ampliaram a produção e foram protegidas das importações pelo Estado. Com o avanço da globalização, as multinacionais adotaram a estratégia do carro mundial e incluíram as subsidiárias das matrizes na divisão internacional do trabalho, reduzindo ainda mais as margens de manobra do setor fornecedor nacional (POSTHUMA, 1997, HUMPRHEY; MEMEDOVIC, 2003). Já prejudicado por esta nova estratégia das montadoras, o setor fornecedor passou a competir com os produtos importados devido às políticas de abertura da era Collor. Sem contar com a mesma proteção destinada às montadoras, o setor fornecedor nacional foi gradualmente marginalizado para a produção de bens de menor valor agregado e de menor tecnologia, ampliando a dependência do Brasil da tecnologia importada. 
A trajetória chinesa: da baixa produção à entrada das multinacionais

A partir de 1949, a economia da China foi completamente reorientada para a formação de um complexo industrial através do controle direto do governo. O país adotou a estratégia de "big push", em que os recursos foram mobilizados para a indústria. O governo de Mao Tsé-Tung focou nas áreas consideradas estratégicas, com efeitos de derramamento nos demais setores econômicos, resultando na emergência de novos ramos, como o de equipamentos elétricos, fertilizantes químicos e o automotivo (NAUGHTON, 2006). Seus dirigentes acreditavam que o setor automotivo ajudaria na reativação da economia, através da geração de empregos e dos efeitos de encadeamento; na mecanização da agricultura, ampliando a produtividade para que o país fosse capaz de sustentar sua crescente população; na melhoria das capacidades de segurança, transporte e comunicação (TAN, 2013). A China adotou ainda o sistema de Planos Quinquenais, baseados no modelo soviético e adaptado às condições locais. ${ }^{8}$

Em 1950, representantes da China e da URSS se reuniram e assinaram o Tratado de Amizade, Aliança e Assistência Mútua Sino-Soviética, que se traduziu em uma série de projetos conjuntos de engenharia para a reconstrução da infraestrutura chinesa, que incluíam a instalação de uma fábrica de caminhões durante o Primeiro Plano Quinquenal (1953-1957). Em 1951, o governo escolheu a cidade de Changchun, na região da Manchúria para a edificação da primeira planta automotiva, chamada de First Auto Works, ou FAW (FAW, 2016). A localização geográfica era estratégica devido ao fácil acesso ao exterior; à infraestrutura desenvolvida durante a ocupação japonesa; à proximidade com a URSS e à presença de minério de ferro para a produção de aço, que seria essencial para a indústria automotiva. Diversos conselheiros soviéticos foram enviados para a China de modo a orquestrar a construção da fábrica, a produção dos veículos e o treinamento dos funcionários (THUN, 2006, TAN, 2013).

Além da FAW, os governos provinciais e municipais iniciaram suas próprias operações para a manufatura de veículos e componentes. Logo foram estabelecidas plantas em outras cidades, como Pequim e Nanquim (CHINA, 2007). A partir de meados da década de 1950, o governo central reconheceu a necessidade de produzir carros de

\footnotetext{
${ }^{8}$ Segundo Middlesworth (2013), os planos quinquenais eram o mecanismo básico de planejamento do governo, baseado no estabelecimento de metas e objetivos para os setores econômicos e para o desenvolvimento de áreas estratégicas. Naughton (2006) ressaltou que o modelo institucional soviético de tecnologia industrial e design organizacional foi implantado, mas, desde o princípio, teve que ser adaptado às condições próprias da China.

CSOnline - Revista Eletrônica de Ciências Sociais, Juiz de Fora, n. 25 (2017), pp. 1-296.
} 
passeio. Em 1958, dois anos depois do lançamento do caminhão Jiefang, a FAW iniciou a produção de seu carro Hongqi, ou Bandeira Vermelha. O veículo era exclusivamente voltado para o uso de oficiais do governo e do partido, uma vez que a propriedade privada de veículos era proibida (HOLWEG; LUO; OLIVER, 2005, TAN, 2013). Em 1958, a planta automotiva de Xangai, a SAIC, também iniciou a produção de seus carros de passeio, o Feng Huang. ${ }^{9}$ Em nenhuma planta chinesa, a produção de caminhões e carros de passeio atingiu uma escala desejável, devido à orientação da produção para o trabalho nas minas e indústrias, para os oficiais do governo e para as frotas de taxi (THUN, 2006).

Na década de 1960, o contexto externo da China se alterou. Devido à morte de Stálin, em 1953, às posteriores denúncias de Khrushchov e à repercussão internacional causada pela da fome do Grande Salto para Frente, a relação entre a China e a URSS se deteriorou, resultando em um afastamento a partir de 1959, aprofundado em 1962. Como consequência, a URSS chamou de volta para o país seus técnicos, encerrou contratos e eliminou projetos de assistência econômica. Em resposta, o governo chinês procurou seguir um modelo autônomo e original de desenvolvimento. Paralelamente, a China se envolveu num conflito fronteiriço com a Índia em 1962 e, três anos depois, em 1965, se viu ameaçada pela Guerra do Vietnã (HOLWEG; LUO; OLIVER, 2005).

Em 1964, Mao alterou a política de desenvolvimento do país, baseada no novo contexto externo, e optou pela criação de um programa voltado para as províncias no interior, o Terceiro Front, cujo objetivo era a interiorização da malha industrial chinesa, uma vez que essa se concentrava no litoral e no nordeste e, em caso de ataque, a China poderia ter sua produção afetada (NAUGHTON, 2006). No setor automotivo, foram estabelecidas uma série de plantas de caminhões médios e pesados em regiões montanhosas, interioranas e longe das fronteiras, como a Second Auto Works (SAW), a Sichuan Auto Works e a Shanxi Auto Works. Todas estas novas plantas foram planejadas, construídas e operadas pelo pessoal proveniente das fábricas edificadas durante o período de colaboração com os soviéticos (EUN; LEE, 2002). ${ }^{10}$

Ao final da era Mao, a propriedade das plantas do setor automotivo era Estatal, podendo ser de responsabilidade do governo federal, provincial ou municipal. O mais comum era que a montadora coordenasse a produção do veículo de forma vertical. A

\footnotetext{
${ }^{9}$ De acordo com a SAIC (2016), o mercado chinês ficou dividido entre o Hongqi da FAW ao norte e o Feng Huang ao sul.

${ }^{10}$ Por exemplo, engenheiros, trabalhadores, máquinas e equipamentos da FAW foram transferidos para o planejamento, execução e operação da SAW. Segundo a FAW (2016), cerca de 4.200 funcionários da empresa foram transferidos para a nova montadora. CSOnline - Revista Eletrônica de Ciências Sociais, Juiz de Fora, n. 25 (2017), pp. 1-296.
} 
produção de automóveis era voltada para o mercado interno, sendo caminhões para os trabalhos nas indústrias e minas e os carros de passeio para o uso de oficiais do governo e frotas de taxi. As políticas adotadas na China, por razões estratégicas, priorizaram um grande número de plantas, mas que reduzia as economias de escala e, como consequência, a produção. Em 1957, foram produzidos menos de 8 mil unidades e este valor atingiu o número de 150 mil em 1978.

Neste ano, dois após a morte de Mao, Deng Xiaoping iniciou uma série de reformas de modo a alterar o desenvolvimento econômico chinês, baseando-se na premissa de que para manter o poder e a legitimidade do Partido Comunista Chinês (PCC) era preciso entregar bens de consumo e melhorar a qualidade de vida da população, naquilo que foi chamado de socialismo com características chinesas (LAMPTON, 2013). Inúmeras reformas pró-mercado foram tomadas na agricultura, na indústria e na administração a partir da década de 1970, como a reforma nas comunas rurais e na apropriação dos excedentes agrícolas (HEADEY; KANBUR; ZHANG, 2005), a criação das Zonas Econômicas Especiais (NAUGHTON, 2006), o fomento às empresas aldeãs (DELGADO, 2015), a reforma nas empresas estatais e nas leis trabalhistas e a descentralização do poder do Estado (THUN, 2006). Uma das mais importantes reformas foi a lei das joint ventures, promulgada em 1979, que permitiu o estabelecimento de joint ventures entre uma empresa chinesa e uma estrangeira, com o objetivo de ampliar a cooperação econômica internacional e a troca de tecnologia, sendo que a parceira nacional deveria ter o controle de ao menos metade da nova empresa (CHINA, 1979).

Para o setor automotivo também foram dirigidas reformas. A partir de 1978, consternados com a importação e com a escassez de automóveis no mercado interno, o governo central entendeu que era preciso tornar as empresas estatais mais produtivas e competitivas. Assim, no Sétimo Plano Quinquenal (1986-1990), o setor automotivo foi priorizado e elevado a pilar da economia nacional (CHINA, 2015). Os governos locais, incentivados pela descentralização política e econômica, que permitia maior retenção de impostos no nível local, aderiram ao projeto do governo central e vinte e quatro das trinta e uma províncias chinesas elegeram o setor automotivo como pilar de sua indústria, incentivando ou criando novas empresas montadoras e fornecedoras. A maior parte destas empresas era pequena, com produção média de 10 mil veículos anuais, o que resultou na intensificação de dilemas já identificados no período anterior, como as menores economias de escala, a redundância dos investimentos, a duplicação de projetos de 
tecnologia, o protecionismo e a competição entre as províncias e a importação de tecnologia defasada (LUO, 2006, WEDEMAN, 2011). ${ }^{11}$

Neste contexto, se desenharam os elementos que compuseram a política de 19871988: o foco nos carros de passeio para o consumo interno, a formação de joint ventures entre empresas estatais nacionais e as multinacionais, com o objetivo de trocar mercado interno por tecnologia ${ }^{12}$ e a elevação de altas barreiras tarifárias. O governo central anunciou que iria priorizar o desenvolvimento de suas três maiores montadoras: a FAW, a Dongfeng, antiga SAW, e a SAIC, dentro do programa chamado de "Três Grandes". A premissa do governo central era contornar os problemas derivados da alta descentralização do setor, limitando a entrada e o número de empresas, formando maiores economias de escala e priorizando o desenvolvimento de campeões nacionais. Os governos locais foram proibidos de estabelecerem novas plantas, mas devido à descentralização, muitas províncias desrespeitaram esta orientação, estabelecendo plantas montadoras disfarçadas de fornecedoras de peças. Paralelamente, grupos burocráticos e militares pressionaram o governo central, que revisou o número de empresas e incluiu a Tianjin Automotive Industry Corporation (TAIC) e as duas joint ventures já formadas pelas montadoras de Pequim e de Cantão. Deste modo, a política passou então a ser conhecida como "Três grandes e três pequenas". Em seguida, no alvorecer da década de 1990, a política foi novamente revisada, com a inclusão da Chang'an Automobile Co. Ltd. e da Guizhou Aviation Industry Corporation, sendo, a partir de então conhecida como “Três Grandes, três pequenas e duas minis" (LUO, 2006, WEDEMAN, 2011).

Assim, a partir desta política, quase todas as joint ventures entre uma empresa estrangeira e uma doméstica, eram formadas por empresas destacadas nesta política (CHU, 2011). O governo transferiu para o mercado o sucesso das empresas, esperando que a competição entre elas levasse à redução no número de empresas e à ampliação da produção e das economias de escala. Esta política consolidou também a alteração do foco da produção automotiva chinesa de caminhões pesados para caminhões leves e carros de

\footnotetext{
${ }^{11}$ Entre 1980 e 1986, o número de montadoras na China saltou de cinquenta e seis para cento e quatorze. Além da inauguração de novas plantas, as antigas plantas de armamentos que eram de propriedade das administrações aeroespacial e aeronáutica foram convertidas para a produção de automóveis para sobreviver em uma era mais pacificada. Dentro da burocracia, alguns ministérios de comando dos militares também iniciaram a produção de veículos. Esta fragmentação do setor pode ser observada tanto no número de plantas, quanto na distribuição geográfica, que afetou as economias de escala e a produção total (LUO, 2006, CHINA, 2007).

${ }^{12}$ Para atrair o investimento externo, o governo ofereceu incentivos como terras e isenções, mas exigia contrapartidas, como a formação de joint ventures, a limitação da participação estrangeira a $50 \%$ e a definição de que a empresa estrangeira poderia se ligar a somente duas empresas.

CSOnline - Revista Eletrônica de Ciências Sociais, Juiz de Fora, n. 25 (2017), pp. 1-296.
} 
passeio (TAN, 2013). Por fim, a política ainda inseriu a exigência de que, nas joint ventures, se respeitassem taxas de conteúdo local para poder importar peças e componentes com tarifas decrescentes. Esta política de conteúdo local foi bem vista pelos oficiais do governo e das empresas locais, que enxergaram uma oportunidade para o seu próprio desenvolvimento. Esperava-se uma rápida localização da produção de peças e componentes nos carros fabricados pelas joint ventures. Todavia, as montadoras estrangeiras resistiram aos produtos locais até que padrões de qualidade e segurança fossem atingidos e o monopólio exercido pelas empresas estrangeiras sobre as técnicas mais avançadas, fez com que a capacidade de pesquisa e desenvolvimento se tornasse uma barreira para as empresas nacionais (MIDDLESWORTH, 2013).

Em 19 de fevereiro de 1994 foi promulgada pelo governo central a Política Formal sobre o Desenvolvimento da Indústria Automotiva ou, mais comumente conhecida como a Política Automotiva de 1994. A política reiterava diversos pontos e objetivos estabelecidos nos planos quinquenais anteriores e na política de 1987 e diagnosticou quatro grandes problemas no setor automotivo chinês: a proliferação do número de empresas, o processo caótico de aprovação de projetos, a duplicação de projetos de importação de tecnologia e o desenvolvimento lento das empresas e do conteúdo local nos veículos de design estrangeiro. Como objetivos ela estabeleceu a formação de grandes grupos em larga escala, o aprimoramento da indústria de componentes, a criação de capacidade de desenvolvimento de produtos automotivos e o encorajamento da propriedade privada de veículos. A política propôs que o Estado apoiaria a instalação de institutos de pesquisa e desenvolvimento e a formação de joint ventures entre empresas nacionais e estrangeiras para a cooperação em $\mathrm{P} \& \mathrm{D}$, destinando uma série de incentivos fiscais para as empresas que cumprissem requisitos mínimos de produção e venda e destinassem recursos para a pesquisa e desenvolvimento (CHINA, 1994). Em suma, a política de 1994 tinha como objetivo incentivar a concentração da indústria, através da formação de campeãs nacionais; expandir a produção; eliminar a produção de pequena escala; fomentar as exportações, regular a formação de joint ventures e estimular a competição de mercado, privilegiando as empresas com maior propensão ao desenvolvimento tecnológico.

Como consequências das políticas de 1987 e de 1994, a propriedade do setor automotivo foi alterada, com a introdução das empresas estrangeiras. Logo os veículos produzidos pelas joint ventures, como o Santana da SAIC-VW, passaram a dominar o mercado interno chinês. Contudo, seguindo as orientações da lei, as empresas estrangeiras CSOnline - Revista Eletrônica de Ciências Sociais, Juiz de Fora, n. 25 (2017), pp. 1-296. 
não poderiam ter mais de $50 \%$ da propriedade da joint venture e ainda eram obrigadas a transferirem tecnologia para as empresas chinesas. A partir daí, um novo dilema se origina na indústria automotiva chinesa, em que as empresas nacionais reclamam que a transferência de tecnologia não ocorre, mas se contentam com o crescimento da produção e de seus lucros advindos das operações em conjunto com as empresas estrangeiras. Paralelamente, as multinacionais concentram as operações de maior tecnologia e maior valor agregado, uma vez que a transferência de tecnologia poderia favorecer o desenvolvimento de um competidor no futuro, deixando as empresas chinesas com as atividades mais básicas do setor. O governo central não conseguiu reduzir o número de empresas na China, mas através de suas políticas expandiu a produção de automóveis, passando de 185 mil em 1978 para 1, 35 milhão em 1994 (CHU, 2011).

Conclusão

As diferentes configurações e estratégias adotadas pelo Brasil e pela China no processo de instalação de seus setores automotivos, condicionou as políticas implementadas no período de abertura econômica e reforma. No Brasil, no período de catching up, a entrada precoce do capital externo eliminou a participação do capital nacional no setor de montadoras no primeiro período de crise enfrentado pela economia brasileira, ainda em meados da década de 1960. Sem ter como recorrer a empréstimos estrangeiros ou resistir aos ciclos de menor consumo e num contexto de pouco auxílio do governo federal, as empresas de capital nacional não resistiram à concorrência das multinacionais. Restava, porém, uma forte presença do capital nacional no setor fornecedor.

Na década de 1990, em função das reformas na estrutura do setor automotivo, como o carro mundial e a estratégia de internacionalização das empresas fornecedoras das matrizes, em conjunto com as políticas do governo de abertura econômica, o capital nacional presente no setor fornecedor foi atingido pela concorrência, e o setor fornecedor brasileiro se desnacionalizou. A Câmara Setorial Automotiva foi eficaz em revitalizar o setor automotivo como um todo, mas incapaz de reverter a desnacionalização - ainda que isto não estivesse no horizonte da política. Deste modo, os acordos setoriais tiveram resultados questionáveis do ponto de vista estratégico, como transferência de capital para o exterior, baixa geração de empregos e desnacionalização do setor fornecedor, principalmente em setores de maior densidade tecnológica.

CSOnline - Revista Eletrônica de Ciências Sociais, Juiz de Fora, n. 25 (2017), pp. 1-296. 
$\mathrm{Na}$ China, por seu turno, o processo de catching up legou um setor automotivo estatal, marcado pela baixa produção, que era voltada para o mercado interno, assim como no Brasil. Contudo, enquanto no Brasil foi priorizado o setor de carros de passeio para o consumo, na China, a produção era de caminhões destinados para as atividades extrativas e industriais e nas limusines de luxo para o uso de oficiais do governo e das frotas de taxi. Ao contrário do Brasil, onde a produção se concentrou na região sudeste, ao longo da década de 1950 e 1960, o governo chinês adotou uma estratégia de dispersão da produção industrial em toda a China, temendo que uma invasão estrangeira inviabilizasse a indústria do país como um todo. Deste modo, o setor automotivo chinês se configurou pela dispersão regional, pela baixa produção e pelo domínio das empresas estatais.

Após a morte de Mao, ao final da década de 1970, a China entrou em um período de reformas econômicas e sociais que visaram manter o controle político do PCC. Para o setor automotivo foi adotada uma estratégia distinta da anterior, possibilitando agora a entrada de montadoras multinacionais, ainda que sob a forma de joint ventures, com objetivos estratégicos específicos, tais como a mudança de foco para carros de passeio, concentração industrial, aumento da produção e transferência tecnológica das empresas multinacionais estrangeiras para as nacionais estatais. O objetivo de concentração industrial não foi atingido, uma vez que, devido à descentralização, os governos locais aproveitaram as brechas para instalarem novas montadoras de veículos. Contudo, a produção de veículos na China foi ampliada e foi permitida a propriedade privada de veículos.

Apesar das diversas falhas, as políticas chinesas do período de reforma passaram a ter no horizonte a questão do incentivo à pesquisa e ao desenvolvimento (P\&D) nas empresas nacionais, consolidando a ideia que a inovação seria um componente central para a equiparação com os países centrais, contrastando, portanto, com o caso brasileiro, que somente passou a considerar a centralidade da $\mathrm{P} \& \mathrm{D}$ nas políticas do século XXI. Observamos, enfim, que enquanto no Brasil ocorreu a desnacionalização do segmento fornecedor e, cada vez mais, o país se tornou dependente tecnologicamente das matrizes das montadoras e fornecedoras, a China optou por uma estratégia voltada para a ampliação da produção e transferência tecnológica nas joint ventures das empresas multinacionais para as estatais, e, uma vez que tal estratégia tenha encontrado limites, optou pelo desenvolvimento de capacidades inovativas nas empresas nacionais. Assim, acreditamos que para obter sucesso nas políticas industriais, se faz necessário considerar a inovação e a P\&D como elementos estratégicos centrais para o desenvolvimento CSOnline - Revista Eletrônica de Ciências Sociais, Juiz de Fora, n. 25 (2017), pp. 1-296. 
econômico e para a solução de diversos dilemas, como as desigualdades regionais e sociais e a inserção no comércio internacional.

Bibliografia

AMSDEN, Alice (2009). A ascensão do "resto": os desafios ao Ocidente de economias com industrialização tardia. São Paulo: Unesp.

ANDERSON, Patrícia. (1999). Câmaras setoriais: história e acordos firmados - 19911995. In: Texto para discussão $n^{\circ}$ 667. IPEA.

ANFAVEA (2015). Anuário da Indústria Automobilística Brasileira. São Paulo. Disponível em: <http://www.anfavea.com.br/anuario2015/Anuario2015.zip>. Acesso em: $11 / 03 / 2015$

ARRIGHI, G. (1997). A Ilusão do Desenvolvimento. $2^{\mathrm{a}}$ ed. Petrópolis-RJ: Vozes.

ARTHUR, Brian. (1990). Positive feedbacks in the Economy. IN: Scientific American, v.262, n.2, p.92-99.

BEDÊ, Marco Aurélio (1997). A política automotiva nos anos 90. In: ARBIX, Glauco e ZILBOVICIUS, Mauro (orgs.) De JK a FHC: a Reinvenção dos carros. São Paulo: Scritta.

BERNARDI, Bernardo. B. (2012). O conceito de dependência da trajetória (path dependency): definições e controvérsias teóricas. IN: Perspectivas, São Paulo, v.41, p.137-167.

BRASIL (1956). Decreto no 39.412, de 16 de Junho de 1956. Estabelece normas diretoras para a criação da Indústria Automobilística Brasileira e institui o Grupo Executivo para aplicação dessas normas. Disponível em:

$<$ http://www2.camara.leg.br/legin/fed/decret/1950-1959/decreto-39412-16-junho-1956332154-publicacaooriginal-1-pe.html>. Acesso em: 20/11/2014

(1993). Decreto no 799 de 17 de Abril de 1993. Disponível em:

<http://www.planalto.gov.br/ccivil_03/decreto/1990-1994/D0799.htm>. Acesso em: 10/07/16.

(1995). Decreto no 1.391, de 10 de Fevereiro de 1995. Disponível em: <http://www.planalto.gov.br/ccivil_03/decreto/1995/D1391.htm>. Acesso em: 10/07/16.

CASTRO, Lavínia Barros de. (2011b). Privatizações, abertura e desindexação: a primeira metade dos anos 90 (1990-1994). IN: GIAMBIAGI, Fábio et. al. (orgs.). Economia brasileira contemporânea: 1945-2010. $2^{\text {a }}$ Ed. Rio de Janeiro: Elsevier.

CHINA. (1979). Law of the People's Republic of China on Chinese-Foreign Equity

Joint Ventures. Disponível em: <http://www.npc.gov.cn/englishnpc/Law/200712/13/content_1384083.htm >. Acesso em: 06/10/2016.

CSOnline - Revista Eletrônica de Ciências Sociais, Juiz de Fora, n. 25 (2017), pp. 1-296. 
(1994). Política Formal sobre o Desenvolvimento da Indústria Automotiva.

Disponível em:

<http://english.mofcom.gov.cn/aarticle/lawsdata/chineselaw/200211/20021100050498.h tml>. Acesso em: 10/03/2015.

(2007). China Business Guide: Auto Volume. Economic Information Department - Council for the promotion of international trade. Disponível em: $<$ http://www.ccpit-france.org/Chinese_Business_Guide_Auto_Volume.pdf $>$. Acesso em: 23/03/2016.

(2015). The 7th Five Year Plan (1986-1990). Disponível em:

$<$ http://www.china.org.cn/english/MATERIAL/157620.htm>. Acesso em: 10/06/2015. CHU, Wan-Wen. (2011) How the Chinese government promoted a global automobile industry. In: Industrial and Corporate Change. Oxford University Press. P. $1-42$.

DELGADO, I. G. (2015). Política industrial na China, na Índia e no Brasil: legados, dilemas de coordenação e perspectivas. Texto para discussão 2059. Instituto de Pesquisa Econômica Aplicada. Brasília, Rio de Janeiro.

EUN, Jong-Hak e LEE, Keun (2002). Is an industrial policy possible in China? The case of the Automobile Industry. In: Journal of International and Area Studies. Vol. 9, $\mathrm{n}^{\mathrm{o}}$ 2, 2002, p;1-21. Disponível em:

<http://www.jstor.org/stable/43107062?seq=1\#page_scan_tab_contents>. Acesso em: $10 / 10 / 2015$.

FARO, Clovis de; SILVA, Salomão L. Quadros da. (1991). A década de 50 e o Programa de Metas. In: GOMES, Ângela de Castro. (1991). O Brasil de JK. Rio de Janeiro: Ed. Da Fundação Getúlio Vargas/ CPDOC.

FAW (2016). About FAW: history. Disponível em:

<http://www.faw.com/aboutFaw/aboutFaw.jsp?pros=forward.jsp\&phight=580\&about=f orword>. Acesso em: 23/03/2016.

HEADEY, Derek; KANBUR, Ravi; ZHANG, Xiaobo (2008). China's growth strategies. In: KANBUR, Ravi; ZHANG, Xiaobo (eds.). Governing rapid growth in China: equity and institutions. Routledge Studies in the Modern World Economy. Disponível em:

<http://www.arts.cornell.edu/poverty/kanbur/China\%27sGrowthStrategies.pdf >. Acesso em: 09/12/2015.

HOLWEG, Matthias, LUO, Jian Xi e OLIVER, Nick (2005). The past, present and future of China's automotive industry: a value chain perspective. UNIDO. The Cambridge-MIT Institute. Disponível em:

<http://www.research.ed.ac.uk/portal/files/7765689/Oliver.pdf>. Acesso em:

HUMPHREY, John; MEMEDOVIC, Olga. (2003). The global automotive industry value chain: what prospects for upgrading by developing countries. UNIDO. Sectoral Studies Series. Viena. 
LAMPTON, David (2013). Following the leader: ruling China, from Deng Xiaoping to Xi Jinping. Berkley, Los Angeles, University of California Press

LATINI, Sydney (2007). A implantação da indústria automobilística no Brasil: da substituição de importações ativa à globalização passiva. São Paulo: Alaúde Editorial.

LEOPOLDI, Maria Antonieta P. (1991). Crescendo em meio à incerteza: a política econômica do governo JK (1956-60). In: GOMES, Ângela de Castro. (1991). O Brasil de JK. Rio de Janeiro: Ed. Da Fundação Getúlio Vargas/ CPDOC.

LIMONCIC, Flávio (1997). A civilização do automóvel: a instalação da indústria automobilística no Brasil e a via brasileira para uma improvável modernidade fordista 1956-1961. Dissertação de Mestrado, UFRJ.

LUO, Jiangxi (2006). The impact of government policies on industrial evolution: the case of China's Automotive Industry. Dissertação de Mestrado em Ciências em Tecnologia e Política do MIT.

MIDDLESWORTH, Huston (2013). Engines of change: China's rise and the Chinese auto industry. CMC Senior Theses. Paper 766. Disponível em:

$<$ http://scholarship.claremont.edu/cgi/viewcontent.cgi? article $=1772 \&$ context $=$ cmc_thes es>. Acesso em: 07/04/2016.

NAUGHTON, Barry (2006). The Chinese economy: transitions and growth.

Cambridge: The MIT Press.

NEGRO, Antonio Luigi (1997). Servos do tempo. In: ARBIX, Glauco e

ZILBOVICIUS, Mauro (orgs.) De JK a FHC: a Reinvenção dos carros. São Paulo:

Scritta.

PIERSON, Paul. (2004). Politics in time: history, institutions, and social analysis.

Princeton, NJ: Princeton University Press.

POSTHUMA, Anne Caroline (1997). Autopeças na encruzilhada: modernização desarticulada e desnacionalização. In: ARBIX, Glauco e ZILBOVICIUS, Mauro (orgs.) De JK a FHC: a Reinvenção dos carros. São Paulo: Scritta.

RAMALHO, José Ricardo (1997). O Estado produtor e a Fábrica Nacional de Motores. In: ARBIX, Glauco e ZILBOVICIUS, Mauro (orgs.) De JK a FHC: a Reinvenção dos carros. São Paulo: Scritta.

ROEHE, Nara Simone. (2011). A indústria automobilística e a política econômica do governo Geisel: tensões em uma parceria histórica (1974-1978). Tese (Doutorado em História Econômica) PUC, Porto Alegre, Rio Grande do Sul.

SAIC (2016). Company profile: history and heritage. Disponível em: <http://www.saicgroup.com/english/company_profile/history_and_heritage/index.shtml >. Acesso em: 23/03/2016. 
SAKER, Adriana Corrêa. (2006). Pacto social no Brasil: os acordos tripartites do setor automotivo nos anos 90. Dissertação de Mestrado. Programa de Pós-Graduação da Faculdade de Direito. Universidade Metodista de Piracicaba. 89 p

SHAPIRO, Helen. (1994). Engines of growth: the state and transnational auto companies in Brazil. Cambridge: Cambridge University Press.

. (1996). The mechanics of Brazil's auto industry. In: NACLA's

Report on the Americas. Jan/Fe. Disponível em: <http://www.hartfordhwp.com/archives/42/037.html>. Acesso em: 10/10/2014.

. (1997). A primeira migração das montadoras: 1956-1968. In:

ARBIX, Glauco e ZILBOVICIUS, Mauro (orgs.) De JK a FHC: a Reinvenção dos carros. São Paulo: Scritta.

TAN, Zhaotao (2013). The development of the Chinese automobile industry since 1949: the role of the government. 305fls. Tese. Coventry University, Coventry.

THUN, Eric (2006). Changing lines in China: foreign direct investment, local governments, and auto sector development. New York: Cambridge University Press.

WEDEMAN, Andrew (2011). Crossing the river by feeling for stones or carried across by the current? The transformation of the Chinese automotive sector. In: KENNEDY, Scott. Beyond the Middle Kingdom: Comparative Perspectives on China's Capitalist transformation. Stanford University Press, Stanford, California. 